\title{
A substrate removal processing method for III-V solar cells compatible with low-temperature characterization
}

\author{
J. Villa , I. Ramiro , J.M. Ripalda , E. Antolín , I. García , A. Martí
}

Keywords:

Thin film

Substrate removal

Low temperature

Concentrator solar cells

III-V semiconductors

\begin{abstract}
A B S T R A C T
In this work, we present a substrate removal procedure for solar cells compatible with direct attachment of the epitaxy to a holder through a thermally and electrically conductive interface. In our case this procedure was motivated by the need to develop a processing technique compatible with low-temperature characterization of the devices. The method is based on the use of indium to bond a thin-film epitaxial structure to a silicon support. The adequate properties of indium, namely, low tensile strength and good thermal and electrical conductivity, allow characterizing the devices at very low temperatures without causing strain-induced degradation in the samples. Following this method, we have fabricated and characterized thin-film $(1.74 \mu \mathrm{m}) \mathrm{AlGaAs}$ solar cells with and without a layer of InAs quantum dots. We show the adequacy of our method to measure at low temperatures by means of measuring the photocurrent or quantum efficiency of the devices at different temperatures, ranging from $300 \mathrm{~K}$ to $20 \mathrm{~K}$.
\end{abstract}

\section{Introduction}

For years, there has been interest in the solar cell research and industry in reducing the thickness of conventional thick -a few hundred microns- devices [1-3]. In this context, a thin-film solar cell refers to a device with a thickness that varies from a few microns to a few tens of microns, depending on the absorbing material. The reasons that make thin-film solar cells attractive are diverse. For solar cells made of direct-gap semiconductors, which need only a few microns to absorb most of the sunlight, manufacturing cost could be reduced by reutilizing several times the substrate on which the solar cells structures are grown, following the so-called epitaxial lift-off (ELO) process [4]. Without the thick substrate, the thin-film structures can be transferred onto a flat or curved base or support, e.g., glass [5], quartz substrate, silicon [6], plastic foil [7,8] or metal foil [9]. This makes it possible to incorporate solar cells in flexible electronics designs $[7,8,10]$. Furthermore, removing the substrate is required in inverted solar cells, conceived to increase the flexibility in the design of multijunction solar cells [11,12]. Finally, the combination of a thinfilm structure with light trapping techniques, which effectively increase the optical length of the devices, may lead to physically thin but optically thick (highly absorbent) solar cells [13]. Related to this, thinfilm device processing has also caught the attention of researches working on solar cells based on nanostructures, such as inorganic quantum dot $[14,15]$ or quantum well [16-18] solar cells. In those works, surface texturing [19] of thin-film devices is explored as a means of enhancing low-energy-photon absorption in the nanostructures.

In our group, we have been working for many years on novel solar cell concepts $[20,21]$ using semiconductor quantum dots as absorbing material. Similarly to the case of quantum dot [22] and quantum well photodetectors [23], low-temperature characterization, in particular photocurrent experiments, has been essential to understand the fundamental principles, potential and limitations of solar cells using inorganic nanostructures [24-26]. As previously mentioned, one hot topic on this kind of solar cells is to enhance the absorptivity of the quantum structures by using light trapping mechanisms in thin-film devices. The work carried out so far has proven the beneficial aspects of the light trapping schemes [14-18]. However, the experimental results obtained are limited to room temperature (RT) conditions, since the thin-film processing methods used are not compatible with lowtemperature measurements. The reason is that thin-film solar cells are usually manufactured through the bonding of the solar cell structure and the support with a polymeric epoxy, which is not a good electrical or thermal conductor $[5-8,12]$. This prevents heat dissipation as well as extracting the back contact directly from the rear side of the solar cell. Although some methods have successfully addressed the issue of heat dissipation $[27,28]$, low-temperature characterization has 
not been performed on the processed devices. Only recently, low temperature measurements have been carried out in a thin-film $(50 \mu \mathrm{m})$ device soldered with a conductive epoxy on elastomeric substrates [29]. In the latter work, measurement results at temperatures lower than $150 \mathrm{~K}$ are reported to be abnormal.

In this work, we report on a substrate removal processing method for III-V solar cells compatible with very low temperature characterization $(20 \mathrm{~K})$ and very thin $(1.74 \mu \mathrm{m})$ devices. The key element of our method is the use of indium for bonding the few-micron-thick structure to a silicon flat support. Both indium and silicon are sufficiently good thermal conductors. Using this method we have fabricated and characterized thin-film AlGaAs solar cells with and without a layer of InAs quantum dots (QD). Recently, the transfer onto an external substrate by using an In sheet of a thin-film GaN light-emitting diode has been reported [30]. In that work, only room-temperature operation is reported. We demonstrate our method to be suitable for lowtemperature measurements because it allows for heat dissipation through the rear bonding and does not produce thermal-stress-induced mechanical strain in the thin devices. This is demonstrated by optoelectrical characterization of the fabricated solar cells at different temperatures in the $20-300 \mathrm{~K}$ range. Additionally, we are able to demonstrate sub-bandgap photocurrent and thermal carrier escape in thin-film QD solar cells. Finally, the indium soldering allows electrically back contacting the device, in contrast to other thin-film processing methods [12,29,31,32], in which both the positive and negative contacts must be fabricated on the front side of the device.

\section{Materials and method}

\subsection{Sample description}

Fig. 1 depicts the AlGaAs p-i-n epitaxial solar-cell structures (S1 and S2) fabricated in this work (the drawing is not to scale). Both solar cells have the same structure, except for a layer of InAs quantum dots (QDs) which is present in S2 and not in S1. It is an inverted structure the upper part of the grown structure, $p$ type, will be the bottom part of the completed device, and the bottom part of the structure, $\mathrm{n}$ type, will become the upper part of the device. The device structure was grown at the Instituto de Microelectrónica de Madrid by molecular beam epitaxy

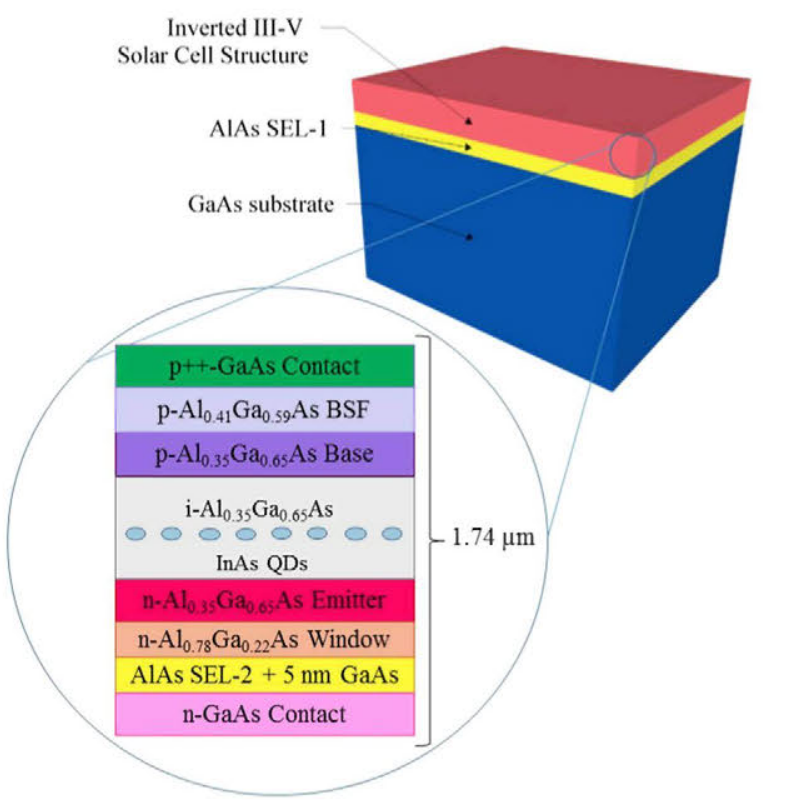

Fig. 1. Sketch of the inverted semiconductor layer structure of the thin-film AlGaAs solar cells. Sample S2 is depicted here. Both samples, S1 and S2, share the same epitaxial structure, except for the InAs QD layer present in sample S2, as it is described in the first paragraph of the sample description.
(MBE) on a 2" n-type (001) GaAs wafer. Following a $300 \mathrm{~nm}$ buffer layer of GaAs, a $100 \mathrm{~nm}$ layer of AlAs was grown to serve as stop etching layer (SEL) for the previously discussed substrate removal process. Henceforth, we will refer to this layer as SEL-1.

The structure is designed as to withstand $\mathrm{n}$-contact annealing. For this reason, SEL-1 is followed by a $300 \mathrm{~nm}$ thick $\mathrm{n}$ type $\left(3 \mathrm{e} 18 \mathrm{~cm}^{-3}\right)$ $\mathrm{GaAs}$ contact layer. A thick layer is necessary to stop gold from diffusing into the active part of the device during contact annealing. To avoid parasitic absorption of the contact layer -which does not contribute to photocurrent generation-, it has to be selectively etched, using the metal grid as a mask. In order to prevent subsequent layers to be etched, a 5-nm AlAs SEL -henceforth SEL-2- is necessary to protect the rest of the epitaxy. Immediately after contact-layer removal, SEL-2 itself is etched in diluted HF. Below SEL-2, a 5-nm GaAs layer is left as protection against oxidation in air of the window layer. The window layer has a $78 \%$ aluminum content and is $30-\mathrm{nm}$ thick. The emitter is $200-\mathrm{nm}$ thick and doped to $5 \mathrm{e} 17 \mathrm{~cm}^{-3}$ with $35 \%$ Al. Thicker emitters were found to compromise the quantum efficiency at short wavelengths, probably due to the minority hole diffusion length being of the same order of magnitude as the emitter thickness. A 600-nm-thick AlGaAs intrinsic layer was grown between the emitter and the base. Embedded in this layer, one layer of InAs QDs was grown in sample S2. The QDs were self-assembled after the deposition of 2 monolayers of InAs. Slab doping with silicon was employed so as to dope the dots with approximately one electron per dot, assuming a QD areal density of 3 . $10^{10} \mathrm{~cm}^{-2}$. A 200-nm-thick Be-doped base was then grown, followed by $200 \mathrm{~nm}$ p+ back surface field (BSF) layer with $41 \% \mathrm{Al}$ to confine minority electrons away from the back side contact. The last epitaxial layer was a $100 \mathrm{~nm}$ thick p++ doped GaAs layer that served as the back contact. The total thickness of the active epitaxial layers is $1.74 \mu \mathrm{m}$. This will also be the thickness of the final device, excluding the metal contacts.

\section{Method}

Our thin-film processing method consists in soldering with indium foil an inverted solar cell structure onto a flat silicon support. Indium is the key element of the method, since it allows both heat dissipation and rear-contacting the device. Indium was employed because of its suitable features; namely, low tensile strength (1.6MPa [33]), and high thermal and electrical conductivity. The low value of indium tensile strength allows low-temperature measurements without strain-induced degradation of the sample. In addition, thermal and electrical conduction allow, respectively, for heat dissipation and back contacting of the devices. The use of indium foils was required in order to maintain the devices flatness after soldering and removal of the substrate. The use of manually spread melted indium, which we had previously employed, resulted in a wrinkled surface and damaged devices.

As flat support we use a p-doped silicon wafer, but other thermally conductive rigid supports can be envisaged. Silicon was chosen since it is a good thermal conductor $\left(150-300 \mathrm{Wm}^{-1} \mathrm{~K}^{-1}\right)$. The solar-cell epitaxy needs an inverted design since it will be soldered upside-down onto the silicon support to then remove the substrate.

After soldering the structure to the support, the semiconductor substrate is removed and the final device is fabricated on the active epitaxial layers by means of standard photolithography techniques and contact fabrication using electroplating techniques. Finally, external connection is made by wiring the thin-film solar cells. These wires are directly connected to both the front and back sides of the solar cells, so it is not necessary to fabricate the two contacts from the front side of the solar cell, thus simplifying the process of contact fabrication.

Below, we describe the main steps of the developed method, illustrated in Fig. 2, applied to our AlGaAs samples:

(a) As-grown sample.

(b) Front side (back contact) metallization of solar cell and Si wafer. 


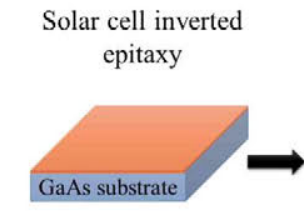

(a)

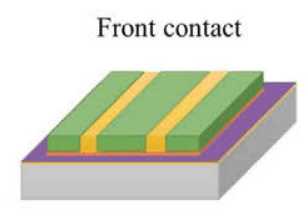

(f)

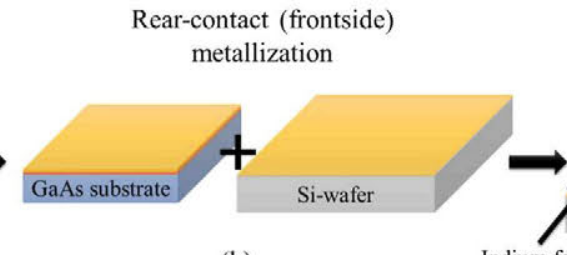

(b)
Soldering in vacuum

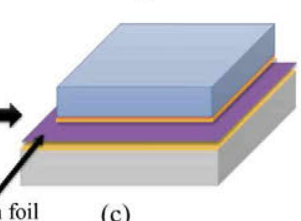

(c)

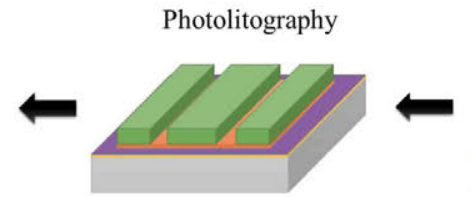

(e)

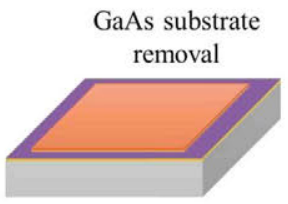

(d)

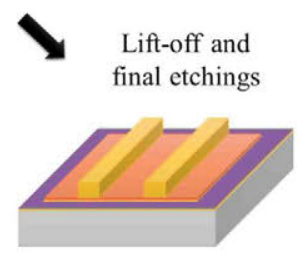

(g)

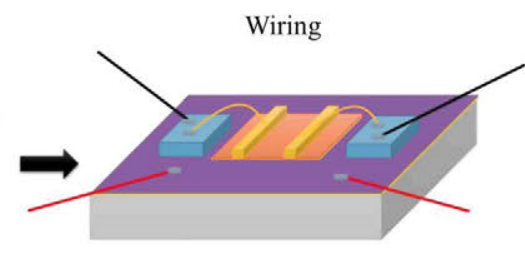

(h)

Fig. 2. Key steps of the developed thin-film solar cell processing method.

The upper surface of the AlGaAs solar cell was coated with $\mathrm{Cr} / \mathrm{Au}$ $(50 \mathrm{~nm} / 500 \mathrm{~nm})$ by thermal evaporation. $\mathrm{Cr} / \mathrm{Au}$ can form an ohmic contact to p-type GaAs. This $\mathrm{Cr} / \mathrm{Au}$ metallic layer will be the back contact of the solar cell and will operate at the same time as back reflector, providing a two-fold increase in the optical length of the absorbing layers.

(c) Soldering in vacuum. The solar cell and Si wafer were placed on a hotplate inside a vacuum chamber with the indium foil $(50 \mu \mathrm{m})$ in between the two Au surfaces. The vacuum chamber prevented the formation of air bubbles in between the metal surfaces. Additionally, an external weight was placed manually onto the wafer stack to add pressure and achieve a homogenous and flat soldering. The hotplate was heated up to $195^{\circ} \mathrm{C}$ and bonding occurred above $160^{\circ} \mathrm{C}$, when indium melted and alloyed with $\mathrm{Au}$.

(d) Substrate removal. The GaAs substrate of the samples was removed by a two-step etching process: (I) a quick non-selective etch of $\mathrm{NH}_{4} \mathrm{OH}: \mathrm{H}_{2} \mathrm{O}_{2}$ (1:1), which etched the majority of the GaAs substrate at a rate of $5-10 \mu \mathrm{m} / \mathrm{min}$, and (II) a slow, selective etch of citric acid: $\mathrm{H}_{2} \mathrm{O}_{2}$ (5:1), which etched the remaining GaAs substrate until reaching the AlAs stop etching layer. SEL-1 was subsequently removed by wet etching in $\mathrm{HF}: \mathrm{H}_{2} \mathrm{O}(1: 10)$ to avoid oxidation of the surface. Thus, the epitaxial $\mathrm{n}-\mathrm{GaAs}$ contact layer surface became the new front side of the thin-film solar cell, where top contacts will be placed.

(e) Photolithography. Standard photolithography techniques were used for creating photoresist patterns on the sample.

(f) Front contact metallization of solar cell. The metal grid as top contact was made by Au electroplating. The thickness of the grid was in the range of $1-3 \mu \mathrm{m}$.

(g) Completion of the devices. Lift-off of the photoresist after metallization, n-GaAs contact-layer etching, SEL-2 removal, and mesa etching completed the process to isolate each solar cell (1-mm radius). For this, standard processing techniques were used.

(h) External electrical connection. Thin gold wires (25- $\mu \mathrm{m}$ diameter) connect the front metal grid of the devices to an external printed circuit board (PCB). The thin Au wires were bonded to the front grid with a silver conductive epoxy. Wedge wire-bonding could not be applied since it strongly damaged our thin $(1.74 \mu \mathrm{m})$ devices. Consequently, the bonding of the thin gold wires on the grid contact had to be manually done. For external connection, thicker copper external wires were soldered with tin to the PCB.

\subsection{Measurement conditions}

For photocurrent and external quantum efficiency (EQE) measurements, samples were mounted on a copper disk and placed in a closedcycle helium cryostat. Light from a halogen lamp was chopped and diffracted with the aid of a Cornerstone $260^{\mathrm{rM}} 1 / 4 \mathrm{~m}$ monochromator M-74100 Newport ${ }^{\oplus}$. The photocurrent detection was done using conventional lock-in techniques (Standford Research Systems ${ }^{\bullet}$ DSP Lock-in Amplifier, Model SR830) and a low-noise current preamplifier (Standford Research Systems ${ }^{\oplus}$, Model SR570).

Current-voltage measurements were performed under approximate AM1.5D solar spectrum and standard measurement conditions. The spectrum was obtained by filtering light from a xenon lamp light with appropriate AM1.5D filters.

Scanning electron microscopy (SEM) images were acquired using two different microscopes. Fig. 3(a) was acquired using an SEM Inspect $^{\mathrm{TM}} \mathrm{F} 50$ operated at $15 \mathrm{keV}$ and different magnifications. Fig. 3(b) was carried out in a JEOL JSM-6335F and it was recorded working at an acceleration voltage of $20 \mathrm{kV}$ and a working distance of $15 \mathrm{~mm}$ at different magnifications.

\section{Results}

\subsection{Microscopy}

Fig. 3(a) shows a SEM image of one solar cell after removal of the substrate (step d in Fig. 2). The indium layer can be seen between the epitaxial solar cell (top thin dark region) and the silicon wafer (bottom region) as a soldering. The thickness of the indium layer after the soldering and the substrate removal was approximately $30 \mu \mathrm{m}$. Fig. 3(b) shows a SEM image of a completed processed device before wiring (step g in Fig. 2). This picture displays both front and back 


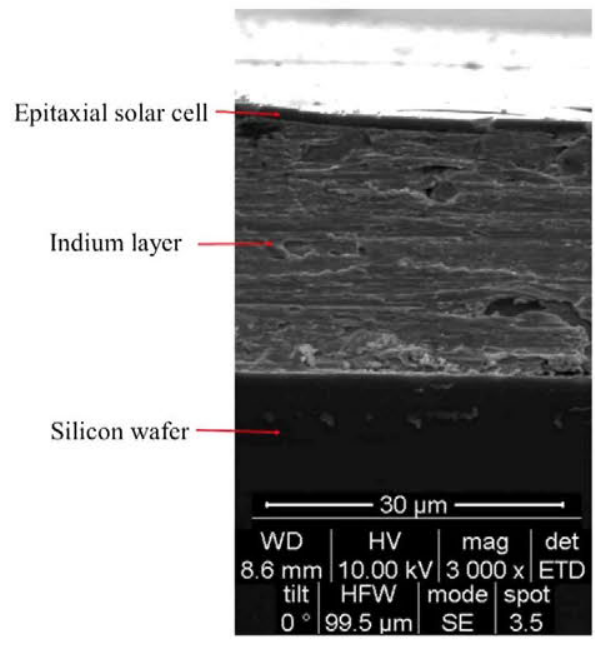

(a)

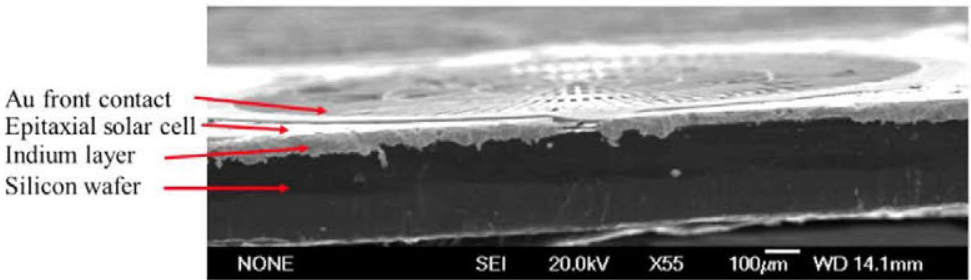

(b)

Fig. 3. SEM images. (a) SEM image of a processed device as in step (d) of Fig. 2. (b) A processed device as in step (g) of Fig. 2.

contacts of the solar cell through the front metal grid and the indium layer, respectively. The epitaxial thin film, too thin to be properly appreciated in this image, is indicated.

Fig. 4 shows some pictures of the fabrication process from the asgrown sample (Fig. 4(a)) to the final device (Fig. 4(d-f)). Fig. 4(c) shows the bare 1.7- $\mu \mathrm{m}$ structure after removal of the substrate. The flat aspect of the epitaxial surface indicates the success of the soldering process. The external copper wires soldered on PCB can be observed in Fig. 4(e). A thin gold wire bonded to the metal grid with silver epoxy is shown in Fig. 4(f). The two big dark spots on the upper part of the

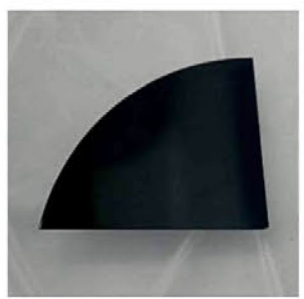

(a) $\longrightarrow$ Fig. 2 (a)

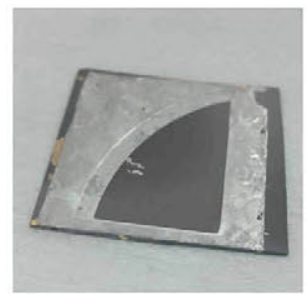

(c) $\longrightarrow$ Fig. 2 (d)

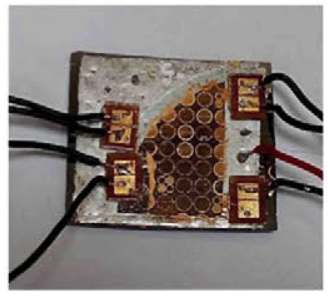

(e) $\longrightarrow$ Fig. 2 (h)

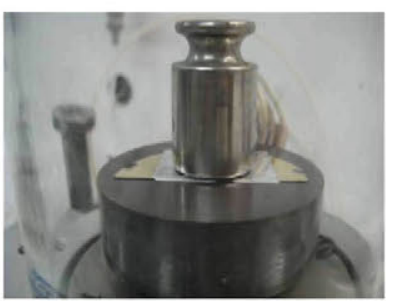

(b) $\longrightarrow$ Fig. 2 (c)

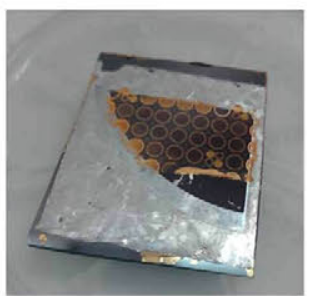

(d) $\longrightarrow$ Fig. 2 (f)

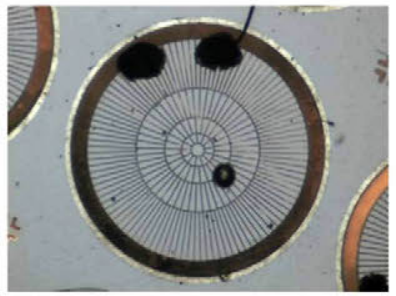

(f)
Fig. 4. Pictures from the fabrication process of the thin-film AlGaAs solar cell on a Si wafer with indium tape. References to Fig. 2 are included for a better tracking of the processing method and its results. device are silver epoxy manually deposited. The small dark spot at the center of the device is a surface defect, probably originated during the soldering in vacuum step.

\subsection{Low temperature photocurrent measurements}

To verify the validity of our processing to perform low temperature characterization, we have measured the spectral photocurrent and EQE in our thin-film AlGaAs samples at different temperatures ranging from $300 \mathrm{~K}$ to $20 \mathrm{~K}$. Photocurrent results for $\mathrm{S} 1$ are shown in Fig. 5. EQE results for S2 are shown in Fig. 6. The theoretical bandgap values of $\mathrm{Al}_{0.35} \mathrm{Ga}_{0.65} \mathrm{As}$ at each temperature, based on the formulae by Vurgaftman and Meter [34], are indicated as dash lines in the graphs. We can see that, in both samples and for all temperatures, photocurrent is produced when the samples are illuminated with suprabandgap light. From the measurements we conclude that the sample is working at the intended temperature, since the experimental absorption threshold energies match the calculated theoretical bandgaps. For the case of S2, sub-bandgap response can be measured at $300 \mathrm{~K}$. This response is attributed to the absorption of light in the InAs QDs. Furthermore, Fabry-Perot oscillations, due to the reduced thickness of our devices, can be appreciated in the sub-bandgap EQE of S2. In the supra-bandgap range of the EQE the high absorptivity of the AlGaAs prevents Fabry-Perot effects. At $195 \mathrm{~K}$ the sub-bandgap EQE of S2 is

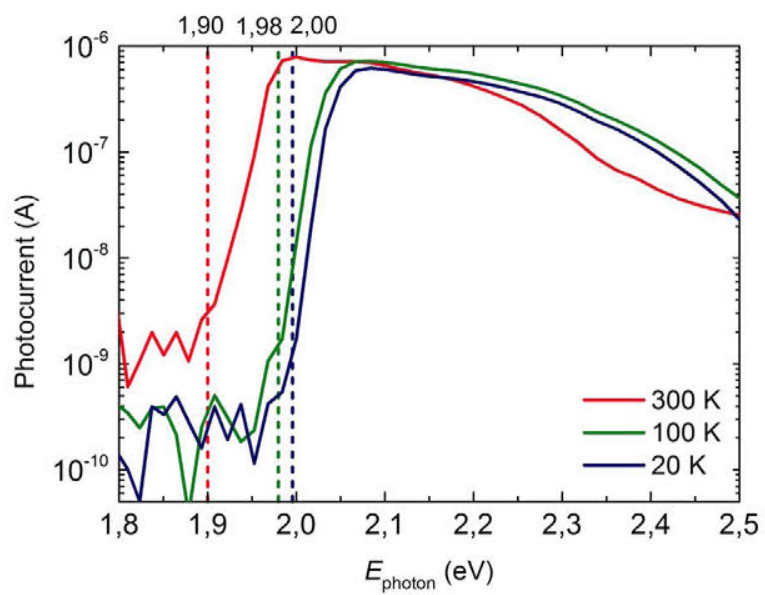

Fig. 5. Photocurrent response of $S 1$ as a function of the excitation energy, at different temperatures. The theoretical bandgaps of the $\mathrm{Al}_{0.35} \mathrm{Ga}_{0.65} \mathrm{As}$ at each temperature are indicated with dashed lines. 


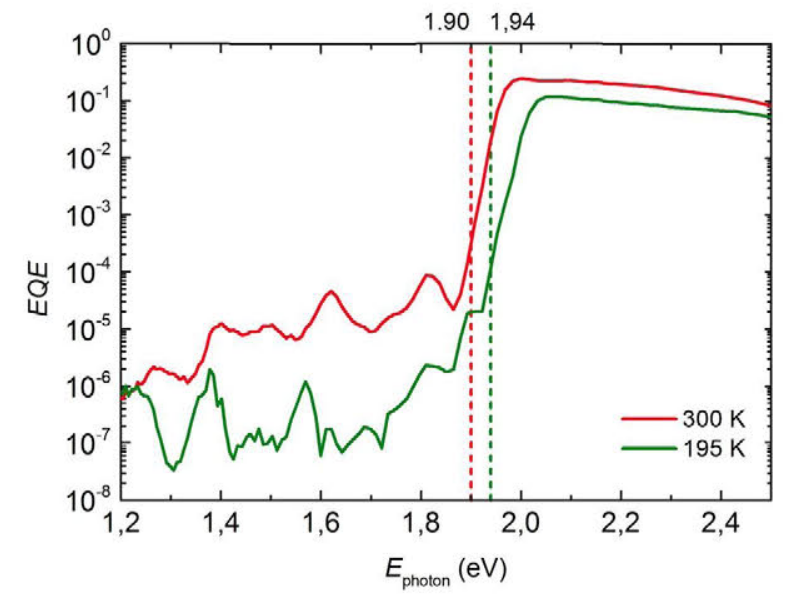

Fig. 6. External Quantum Efficiency measurement, as a function of the excitation energy and at different temperatures, of $\mathrm{S} 2$. The theoretical bandgaps of the $\mathrm{Al}_{0.35} \mathrm{Ga}_{0.65} \mathrm{As}$ at each temperature are indicated with dashed lines.

strongly reduced, due to the inhibition of thermal escape of photocarriers out of the QDs, as it is expected in a high-bandgap quantum dot solar cell, $[35,36]$. Therefore, our processing method has enabled us to verify two key aspects of QD solar cells (sub-bandgap photocurrent and thermal carrier escape) in thin-film devices.

The relatively low value of the supra-bandgap $\mathrm{EQE}$ of $\mathrm{S} 2$ is due to a non-optimized layer structure, the lack of anti-reflective coating and increased carrier recombination introduced by the QDs. However, it must be noted that the results do not show sample degradation at low temperature due to mechanical stress, as intended with the use of indium for the soldering. In fact, at $100 \mathrm{~K}$ and below, the measured photocurrent of S1 increased in the high-energy photon range, resulting probably from an increase in the lifetime of minority carriers in the cell emitter. These results prove the adequacy of our processing method for performing low-temperature characterization on thin-film devices.

\subsection{Room-temperature current-voltage measurements}

The room temperature $J-V$ characteristic for S2 is shown in Fig. 7. The QD solar cell exhibits a $V_{\mathrm{OC}}$ of about $0.52 \mathrm{~V}$. This value is low compared to high-performance AlGaAs solar cells with similar $\mathrm{Al}$ content [37], which have a $V_{\mathrm{OC}}$ greater than $1.3 \mathrm{~V}$. This large voltage drop is attributed to a large increase in the solar cell non-radiative recombination resulting from the inclusion of the dots, as it is common in QD solar cells $[38,39]$. The $J_{\mathrm{SC}}$ value is $2.6 \mathrm{~mA} / \mathrm{cm}^{2}$, in agreement with the measured QE, previously described. Despite the poor performance of the QD devices, the $J-V$ result proves that the thin-film QD

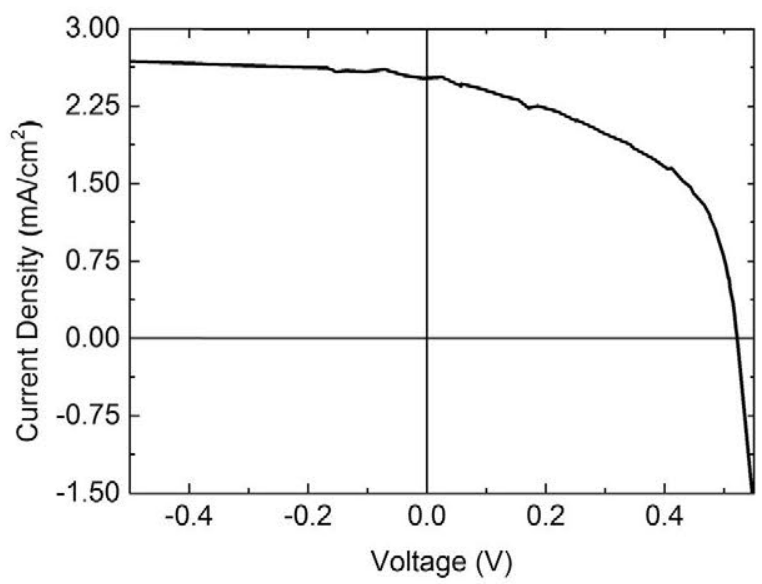

Fig. 7. Current density-Voltage characteristic at room temperature of S2. solar cells are operational.

\subsection{Limitations}

We must point out two limitations in our method. One is the fact that the front contact cannot be annealed, since annealing would temporarily melt the indium layer and degrade the soldering. The second limitation is related to the bonding of the thin wires to extract the electrical current. At the current stage, this bonding had to be manually done -at least for our very thin devices- in order not to degrade the samples.

\section{Conclusions}

A substrate removal processing method using indium soldering has been presented and demonstrated. Our method is compatible with lowtemperature characterization of the processed devices. Using this method, we have soldered $1.74 \mu \mathrm{m}$ inverted AlGaAs solar cells onto a flat silicon support. Through photocurrent measurements, we have demonstrated efficient heat dissipation in the $20-300 \mathrm{~K}$ range. Moreover, the photocurrent results do not show any sign of straininduced degradation at low temperatures. Through EQE measurements, we have demonstrated sub-bandgap photocurrent and thermal carrier escape in samples containing one layer of InAs QDs. We think that the presented method can be useful for the community researching on concentrator thin-film solar cells based on nanostructures (quantum dots and quantum wells) as well as other thin-film technologies.

\section{Acknowledgements}

J. Villa is grateful for the financing of the Spanish Government through the Grant BES-2013-066463. This work has been supported by Comunidad de Madrid through the Project MADRID-PV (Grant S2013/MAE-2780) and by the Spanish National Research Programs through the Projects INVENTA-PV (Grant TEC2015-64189-C3-1-R) and POWERLEO (Grant RTC-2015-3469-3). E. Antolín acknowledges financial support from L'Oréal-UNESCO through a Women in Science Fellowship. I. García is funded by the Spanish Programa Estatal de Promoción del Talento y su Empleabilidad through a Ramón y Cajal grant. The authors acknowledge the Institute of Nanoscience of Aragon (INA) at the University of Zaragoza (Spain) and the National Center for Electron Microscopy at the University Complutense of Madrid for SEM measurements (Fig. 3(a) and 3(b), respectively).

\section{References}

[1] J.N. Mayer, P. Simon, N.S.H. Philipps, T. Schlegl, C. Senkpiel, Current and Future Cost of Photovoltaics, Long-term Scenarios for Market Development, System Prices and LCOE of Utility-Scale PV Systems (Fraunhofer ISE, Study on behalf of Agora Energiewende, Freiburg, 2015), 2015.

[2] Y. Hamakawa, Thin-Film Solar Cells: Next Generation Photovoltaics and Its Applications, Springer Science \& Business Media, Springer Series of Photonics, 2013.

[3] M.A. Green, Thin-film solar cells: review of materials, technologies and commercial status, J. Mater. Sci.: Mater. Electron. 18 (1) (2007) 15-19.

[4] E. Yablonovitch, T. Gmitter, J. Harbison, R. Bhat, Extreme selectivity in the lift-off of epitaxial GaAs films, Appl. Phys. Lett. 51 (26) (1987) 2222-2224.

[5] A. Van Geelen, P. Hageman, G. Bauhuis, P. Van Rijsingen, P. Schmidt, L. Giling, Epitaxial lift-off GaAs solar cell from a reusable GaAs substrate, Mater. Sci. Eng.: B 45 (1) (1997) 162-171.

[6] J. Geisz, S. Kurtz, M. Wanlass, J. Ward, A. Duda, D. Friedman, J. Olson, W. McMahon, T. Moriarty, J. Kiehl, High-efficiency GaInP/GaAs/InGaAs triplejunction solar cells grown inverted with a metamorphic bottom junction, Appl. Phys. Lett. 91 (2) (2007) 3502.

[7] M. Pagliaro, R. Ciriminna, G. Palmisano, Flexible solar cells, ChemSusChem 1 (11) (2008) 880-891.

[8] J.J. Schermer, G.J. Bauhuis, P. Mulder, E.J. Haverkamp, J. van Deelen, A.T.J. van Niftrik, P.K. Larsen, Photon confinement in high-efficiency, thin-film III-V solar cells obtained by epitaxial lift-off, Thin Solid Films 511-512 (2006) 645-653.

[9] T. Takamoto, T. Kodama, H. Yamaguchi, T. Agui, N. Takahashi, H. Washio, T. Hisamatsu, M. Kaneiwa, K. Okamoto, M. Imaizumi, Paper-thin InGaP/GaAs solar 
cells, in: Proceedings of the 2006 IEEE 4th World Conference on Photovoltaic Energy Conference, IEEE, 2006, pp. 1769-1772.

[10] Y. Sun, J.A. Rogers, Inorganic semiconductors for flexible electronics, Adv. Mater. 19 (15) (2007) 1897-1916.

[11] L. Yu, R.S. Kokenyesi, D.A. Keszler, A. Zunger, Inverse design of high absorption thin-film photovoltaic materials, Adv. Energy Mater. 3 (1) (2013) 43-48.

[12] J.F. Geisz, S.R. Kurtz, M. Wanlass, J. Ward, A. Duda, D. Friedman, J. Olson, W. McMahon, T. Moriarty, J. Kiehl, Inverted GaInP/(In) GaAs/InGaAs triple-junction solar cells with low-stress metamorphic bottom junctions, in: Proceedings of the Photovoltaic Specialists Conference, 2008. PVSC'08. 33rd IEEE, IEEE, 2008, pp. $1-5$.

[13] A. Martı, J.L. Balenzategui, R.F. Reyna, Photon recycling and Shockley's diode equation, J. Appl. Phys. 82 (8) (1997) 4067--44075.

[14] T. Sogabe, Y. Shoji, P. Mulder, J. Schermer, E. Tamayo, Y. Okada, Enhancement of current collection in epitaxial lift-off InAs/GaAs quantum dot thin film solar cell and concentrated photovoltaic study, Appl. Phys. Lett. 105 (11) (2014) 113904.

[15] M.F. Bennett, Z.S. Bittner, D.V. Forbes, S. Rao Tatavarti, S. Phillip Ahrenkiel, A. Wibowo, N. Pan, K. Chern, S.M. Hubbard, Epitaxial lift-off of quantum dot enhanced GaAs single junction solar cells, Appl. Phys. Lett. 103 (21) (2013) 213902.

[16] K. Watanabe, T. Inoue, M. Sugiyama, Y. Nakano, Self-Organized Texture of GaAs by Wet Etching for Light Trapping in MQWS Solar 2015, pp. 181-184.

[17] T. Inoue, K. Watanabe, K. Toprasertpong, H. Fujii, M. Sugiyama, Y. Nakano, Enhanced light trapping in multiple quantum wells by thin-film structure and backside grooves With dielectric interface, IEEE J. Photovolt. 5 (2) (2015) 697-703.

[18] K. Watanabe, B. Kim, T. Inoue, H. Sodabanlu, M. Sugiyama, M. Goto, S. Hayashi, K. Miyano, Y. Nakano, Thin-film InGaAs/GaAsP MOWs solar cell with backside nanoimprinted pattern for light trapping, IEEE J. Photovolt. 4 (4) (2014) $1086-1090$

[19] E. Yablonovitch, G.D. Cody, Intensity enhancement in textured optical sheets for solar cells, IEEE Trans. Electron Dev. 29 (2) (1982) 300-305.

[20] A. Luque, A. Marti, Increasing the efficiency of ideal solar cells by photon induced transitions at intermediate levels, Phys. Rev. Lett. 78 (26) (1997) 5014-5017.

[21] A. Luque, A. Marti, C. Stanley, Understanding intermediate-band solar cells, Nat. Photon 6 (3) (2012) 146-152.

[22] P. Martyniuk, A. Rogalski, Quantum-dot infrared photodetectors: status and outlook, Prog. Quantum Electron. 32 (3) (2008) 89-120.

[23] B. Levine, Quantum-well infrared photodetectors, J. Appl. Phys. 74 (8) (1993) R1-R81.

[24] M. Yoshida, H. Amrania, D.J. Farrell, B. Browne, E. Yoxall, N.J. Ekins-Daukes, C.C. Phillips, Progress toward realizing an intermediate band solar cell - sequential absorption of photons in a quantum well solar cell, IEEE J. Photovolt. 4 (2) (2014) $634-638$.

[25] M. Elborg, M. Jo, Y. Ding, T. Noda, T. Mano, K. Sakoda, Two-color photoexcitation in a GaNAs/AlGaAs quantum well solar cell, Jpn. J. Appl. Phys. 51 (6S) (2012) $06 \mathrm{FF} 15$

[26] I. Ramiro, A. Martí, E. Antolín, A. Luque, Review of experimental results related to the operation of intermediate band solar cells, IEEE J. Photovolt. 4 (2) (2014) $736-748$.

[27] C.C. Wang, Z.S. Wu, C.H. Hsu, S.Y. Lien, D.S. Wuu, P. Han, Performance of aSiGe:H thin-film solar cells on high-heat dissipation flexible ceramic printable circuit board, IEEE Trans. Electron Dev. 61 (9) (2014) 3125-3130.

[28] M.-C. Tseng, R.-H. Horng, Y.-L. Tsai, D.-S. Wuu, H.-H. Yu, Fabrication and characterization of GaAs solar cells on copper substrates, IEEE Electron Dev. Lett. 30 (9) (2009) 940-942.

[29] E.H. Lee, J.S. Yeo, J.H. Lee, D.I. Cheong, Temperature-Dependent Photovoltaic Properties of 54- $\mu$ m-thick InGaP/InGaAs/Ge Triple-Junction Solar Cell on Flexible Substrate, Current Applied Physics

[30] Y. Kobayashi, K. Kumakura, T. Akasaka, T. Makimoto, Layered boron nitride as a release layer for mechanical transfer of GaN-based devices, Nature 484 (7393) (2012) 223-227.

[31] T. Yonehara, K. Sakaguchi, N. Sato, Epitaxial layer transfer by bond and etch back of porous Si, Appl. Phys. Lett. 64 (16) (1994) 2108-2110.

[32] J. Lee, J. Wu, J.H. Ryu, Z. Liu, M. Meitl, Y.-W. Zhang, Y. Huang, J.A. Rogers, Stretchable semiconductor technologies with high areal coverages and strainlimiting behavior: demonstration in high-efficiency dual-junction GaInP/GaAs photovoltaics, Small 8 (12) (2012) 1851-1856.

[33] R. Reed, C. McCowan, R. Walsh, L. Delgado, J. McColskey, Tensile strength and ductility of indium, Mater. Sci. Eng.: A 102 (2) (1988) 227-236.

[34] I. Vurgaftman, J.R. Meyer, L.R. Ram-Mohan, Band parameters for III-V compound semiconductors and their alloys, J. Appl. Phys. 89 (11) (2001) 5815-5875.

[35] E. Antolín, A. Marti, C. Farmer, P. Linares, E. Hernández, A. Sánchez, T. Ben, S. Molina, C. Stanley, A. Luque, Reducing carrier escape in the InAs/GaAs quantum dot intermediate band solar cell, J. Appl. Phys. 108 (6) (2010) 064513.

[36] I. Ramiro, E. Antolin, M. Steer, P. Linares, E. Hernandez, I. Artacho, E. Lopez, T. Ben, J. Ripalda, S. Molina, InAs/AlGaAs quantum dot intermediate band solar cells with enlarged sub-bandgaps, in: Proceedings of the Photovoltaic Specialists Conference (PVSC), 2012 38th IEEE, IEEE, 2012, pp. 000652-000656.

[37] K. Takahashi, Y. Minagawa, S. Yamada, T. Unno, Improved efficiency of Al0.36Ga0.64As solar cells with a pp-n-n structure, Sol. Energy Mater. Sol. Cells $66(1-4)(2001) 525-532$.

[38] A. Luque, A. Martı, C. Stanley, N. López, L. Cuadra, D. Zhou, J.L. Pearson, A. McKee, , General equivalent circuit for intermediate band devices: potentials, currents and electroluminescence, J. Appl. Phys. 96 (1) (2004) 903--9909.

[39] P. Lam, J. Wu, M. Tang, D. Kim, S. Hatch, 1. Ramiro, V.G. Dorogan, M. Benamara, Y.I. Mazur, G.J. Salamo, J. Wilson, R. Allison, H. Liu, InAs/InGaP quantum dot solar cells with an AlGaAs interlayer, Sol. Energy Mater. Sol. Cells 144 (2016) 96-101. 